\title{
Negativity in Online News Coverage of Vaccination Rates in Serbia:
}

\section{A Content Analysis}

Aleksandra Lazić and Iris Žeželj

Department of Psychology, Faculty of Philosophy, University of Belgrade

Manuscript status: Postprint, peer-reviewed \& published

This manuscript is published in Psychology \& Health. Please cite as:

Lazić, A., \& Žeželj, I. (2022). Negativity in online news coverage of vaccination rates in Serbia:

A content analysis. Psychology \& Health. https://doi.org/10.1080/08870446.2022.2121962

\section{Author Note}

Aleksandra Lazić (Dhttps://orcid.org/0000-0002-0433-0483 (Conceptualization; Data curation; Formal analysis; Investigation; Methodology; Validation; Visualization; Writing original draft; Writing - review \& editing)

Iris Žeželj Dhttps://orcid.org/0000-0002-9527-1406 (Conceptualization; Methodology; Supervision; Writing - review \& editing)

Correspondence concerning this article should be addressed to Aleksandra Lazić, Department of Psychology, Faculty of Philosophy, University of Belgrade, Čika Ljubina 18-20, 11000 Beograd, Serbia. Email: aleksandra.lazic@f.bg.ac.rs; lazic.ale@gmail.com.

Data Availability Statement: The data that support the findings of this study are openly available in Open Science Framework at https://osf.io/5bkz8.

Disclosure of Interest: The authors report no conflict of interest.

Acknowledgments: This work was supported by the Ministry of Education, Science and Technological Development of the Republic of Serbia under Grant [number 451-03-68/2022-14/ 200163]. We thank Marija Petrović (Dhttps://orcid.org/0000-0001-6422-3957 for her contribution to the intercoder reliability check. This work is part of Aleksandra Lazić's $\mathrm{PhD}$ thesis titled Комуникација обухвата вакиином: Провера претпоставки модела себичне наспрам модела соиијалне рационалности [Соттипісаting vaccination coverage: Testing the selfish versus the social rationality hypothesis], under the supervision of Iris Žeželj, PhD. 


\begin{abstract}
Objective: This content analysis study explored how online news media communicates and frames vaccination rates and herd immunity (the effect where enough people are immune, the virus is contained).
\end{abstract}

Methods: We analyzed 160 vaccination-related news stories by nine highest-trafficked news websites in Serbia, published July-December 2017, around the start of the measles outbreak. We coded both the news story as a whole and every vaccination-rate mention $(N=339)$.

Results: News stories framed current vaccination rates and changes in them in a predominantly negative way (175/241 and 67/98 mentions, respectively) (e.g., "only 50\% vaccinated", "fewer parents vaccinating their children"), especially when referring to the measles vaccine (202/262 mentions). A total of 23/86 of news stories mentioning vaccination rates did not provide any numerical values. Reference groups for vaccination rates were rarely specified. Out of the 32 news stories mentioning herd immunity, 11 explained the effect.

Conclusions: Even routine communication of vaccination rates can be biased through negative frames and imprecise descriptions. Lamenting low immunization rates could activate a negative descriptive social norm (“many people are not getting vaccinated”), which may be especially illadvised in the absence of an explanation of the social benefit of achieving herd immunity through vaccination.

Keywords: descriptive norms; framing; health communication; immunization; mass media; vaccine 


\section{Negativity in Online News Coverage of Vaccination Rates in Serbia: \\ A Content Analysis}

\section{Introduction}

There is ample evidence that mass communication brings about societal and individual changes regarding vaccination. Communities with anti-vaccine campaigns in the local media had lower vaccine uptake (Gangarosa et al., 1998; Mason \& Donnelly, 2000). Changes in the extent of media coverage coincided with changes in vaccination behavior (Ma et al., 2006) and the public's level of vaccine knowledge (Kelly et al., 2009). Furthermore, mass media are often the main source of health- and vaccine-related information. Vaccine hesitant parents often reported relying on the media as their main source of information or being affected by the media reports (Dannetun et al., 2005; Evans et al., 2001; Guillaume \& Bath, 2004). In a 2017 nationally representative survey of Serbian parents, $44 \%$ reported relying on websites, forums, or blogs for vaccine information (UNICEF Serbia, 2018).

The present study focused on understanding the types of messages conveyed through online news media - specifically those related to vaccination rates and herd immunity. Vaccination rate refers to the share of those vaccinated in a population; if a large enough share of the population is immune, the virus is contained. This effect is called herd immunity (Fine et al., 2011). We hypothesized that even the seemingly straightforward reporting of vaccination rates is often biased by the introduction of negativity and frames in communication. We further assumed that one such negative framing strategy - signaling low vaccination rates (e.g., "drop in vaccine rates as measles outbreak looms", "many rates are below the 95\% target") - would be commonly 
employed by the news media. We tested these assumptions by conducting a content analysis of online news media in Serbia, around the start of the measles outbreak in 2017.

\section{Framing in News Stories About Vaccination}

Informative messages disseminated through news media are expected to contain minimal personal opinion and value judgment. However, the mere fact that it needs to be decided how content is presented implies that the media engages in framing practices and in doing so introduces some bias. Framing refers to the words, images, phrases, and presentation styles used when relaying information to the audience (Druckman, 2001). Through framing, the media can affect how members of the public and policymakers think about certain issues and it can realize behavioral changes (e.g., Chong \& Druckman, 2007; Yanovitzky, 2002).

Most of the work on the framing effects in the news media has dealt with emphasis frames. They provide "an interpretation of an issue or policy by emphasizing which aspect of the issue is relevant for evaluating it, without ... providing any new substantive information about the issue" (Leeper \& Slothuus, 2020, p. 154). For example, human papillomavirus (HPV) vaccination may be presented as either cancer prevention or sexually-transmitted infection prevention (Leader et al., 2009).

The present study focused on another type of frames called equivalency frames. While emphasis frames imply that different aspects of an issue or policy may be chosen to build a context around it, equivalency frames imply that even identical pieces of information may be communicated using different, but logically equivalent, descriptions (Tversky \& Kahneman, 1987). The effect of equivalency frames on people's preferences has been demonstrated in different health contexts (Akl et al., 2011; Levin et al., 1998). 
One basic form of equivalency framing is attribute framing, where the frame is applied to a single characteristic of an object or event and is expected to influence the evaluation of that object or event (Levin et al., 1998). For example, framing the HPV vaccine as $70 \%$ effective yielded higher ratings of vaccine effectiveness and more support for policies mandating the vaccine, compared to framing it as $30 \%$ ineffective (Bigman et al., 2010). Even merely describing the same critical information in either a positive or negative light constitutes an attribute frame (Schneider et al., 2005). Thus, the same vaccination uptake may be positively (as high as $50 \%$ vaccinated) or negatively valenced (only $50 \%$ vaccinated).

\section{Negativity in News Stories About Vaccination}

Negativity has always been a part of news reports, including those about vaccination. A review of content analyses of traditional media found that, of the 13 studies coming from a variety of countries, $62 \%$ identified more negative than positive messages about vaccination (Catalan-Matamoros et al., 2019). The negative news messages often framed vaccination around the issues of efficacy, side-effects, and tragic personal stories (Catalan-Matamoros et al., 2019).

The principle that negative events are "more salient, potent, dominant in combinations, and generally efficacious than positive events" (Rozin \& Royzman, 2001, p. 297; see also Baumeister et al., 2001) may affect the selection and production of news stories. People tend to learn more from negative than from positive political information (Bradley et al., 2007) and to be more aroused by and attentive to negative video news content (Soroka et al., 2019). A recent preliminary analysis revealed that negative words in news headlines increase consumption rates (Feuerriegel et al., 2022). There is evidence, however, that, when presented to pro-vaccination individuals, negatively framed statements relating to vaccine side-effects and the scientific 
consensus were not better memorized, were deemed less plausible, and were less appealing to transmit, compared to positively framed statements (Altay \& Mercier, 2020).

\section{Public Communication of Vaccination Rates}

Even though the majority of people worldwide support vaccination (e.g., World Health Organization, 2018; YouGov, 2021), it appears that the news media often focuses on vaccine refusers. Lamenting low vaccination rates may be even considered part of the pro-vaccine rhetoric, as suggested by an analysis of Australian newsprint media (1993-1998) (Leask \& Chapman, 2002). Such a strategy could be seen as problematic as it can distort the perception of group norms surrounding vaccination.

\section{Vaccination Rates as a Source of Normative Influence}

The Focus Theory of Normative Conduct (Cialdini et al., 1990) distinguishes between two types of social norms: descriptive (what most others are doing) and injunctive (what most others approve or disapprove of). It is further assumed that norms influence behavior directly only when they are made salient or focused upon. As a type of summary information about the behavior of a reference group, vaccination rates are probably the most straightforward way of altering the perceptions of descriptive norms surrounding vaccination (Tankard \& Paluck, 2016). As such, they are theorized to motivate behavior by providing evidence of what is likely to be an effective and adaptive course of action (Cialdini et al., 1990).

Describing positive behaviors as typical has the potential to introduce social change in a variety of domains (e.g., Behavioural Insights Team, 2012; Gerber \& Rogers, 2009; Goldstein et al., 2008). Some studies have shown the same effect in the domain of vaccination. Correlational studies have linked perceptions of peer's behavior to stated vaccination intentions (e.g., Allen et 
al., 2009; Graupensperger et al., 2021). In experimental studies, the effects were more mixed: while in some participants reported greater vaccination intentions when knowing that the majority of their peers got vaccinated, compared to when most peers did not (Belle \& Cantarelli, 2021; Hershey et al., 1994; Palm et al., 2021; Romley et al., 2016; see also Ryoo \& Kim, 2021), in other experiments this was not replicated (Clayton et al., 2021; Sinclair \& Agerström, 2021; Xiao \& Borah, 2020). A recent study during the pandemic showed that presenting accurate information about descriptive norms increased people's intentions to accept COVID-19 vaccines (Moehring et al., 2021).

By the same token, depicting an undesirable behavior (vaccine refusal) as regrettably frequent can activate a powerful descriptive norm message - many people are not getting vaccinated (Cialdini, 2003; Cialdini et al., 2006). Therefore, media warnings of low vaccination rates can unintendedly promote non-vaccination as normal and approved by others and might lead people to underestimate the actual vaccination coverage.

Instead of focusing on the current vaccination rate, descriptive norms can draw attention to the change in the vaccination rate over time (e.g., "vaccination rate has increased to $65 \%$ " or "fewer parents vaccinating their children"). Such information can change the perception of the so-called trending or dynamic norms (Mortensen et al., 2019; Sparkman \& Walton, 2017). In previous studies on sustainable consumption and health, dynamic normative messages encouraged positive behavior, even when a change was happening among a minority of people (e.g., Mortensen et al., 2019; Sparkman \& Walton, 2017, 2019). A large US study on flu vaccine uptake found a small positive effect of a dynamic norm message ("More Americans are getting the flu shot than ever") (Milkman et al., 2022). 


\section{Communicating Vaccination Norms With Respect to the Herd-Immunity Effect}

Communicating high vaccination rates can be a double-edged sword due to the possibility of people deciding to free-ride on herd immunity. Herd immunity is the effect where a high enough number of people are immune, the spread of the disease is slowed down or the disease is wiped out altogether. Herd immunity protects everyone, especially the vulnerable (Fine et al., 2011). Through herd immunity, a higher vaccination rate decreases the risk of infection. This provides an incentive for individuals to be free-riders who benefit from the vaccination of others while avoiding the costs of vaccination such as money, time, adverse events, inconvenience (e.g., Böhm et al., 2016; Ibuka et al., 2014).

Communicating herd immunity has the potential to increase vaccination intentions (e.g., Betsch et al., 2017; Lazić et al., 2021; Logan et al., 2018), also in the context of the COVID-19 pandemic (Pfattheicher et al., 2022; Schwarzinger et al., 2021; cf. Freeman et al., 2021). A content analysis of Australian newsprint media (1993-1998) found that the notion of vaccination benefiting the society as well as the individual was rarely promoted (Leask \& Chapman, 2002). At least before the COVID-19 pandemic, it seems that herd immunity was underutilized in vaccine advocacy.

\section{Overview of the Present Study}

Vaccination rates can be a powerful source of normative influence. In addition, the choice of what information to emphasize and whether the information is framed positively or negatively can contribute to the public and policy discussion of vaccination. In contrast to most previous studies on vaccination communication, we did not define negativity as the presence of 
anti-vaccine themes. Instead, we focused on the negativity that can arise from attribute frames of vaccination rates.

This content analysis study focused on two broad research questions: whether and how online news media communicates and frames vaccination rates and whether and how it reports on herd immunity. We examined:

- how often vaccination rates were mentioned and how much prominence was given to them;

- who or what was cited as the source of vaccination rate information;

- what vaccines the rates referred to and whether revaccinations were mentioned;

- what reference groups (populations and territories) vaccination rates referred to;

- whether vaccination rates were presented numerically versus only verbally;

- whether vaccination rates were communicated as static versus dynamic norms;

- whether vaccination rates were framed as the proportion of those vaccinated versus those not vaccinated, as the first attribute frame;

- whether numerically presented vaccination rates were framed in a positive, negative or neutral way, as the second attribute frame;

- how often the term herd immunity was mentioned and explained; and

- how often the herd-immunity threshold (i.e., the critical proportion of the population that must be immunized to stop the disease from spreading) was communicated.

We analyzed Serbian online news stories published from July to December 2017. This sampling period covered the beginning of the measles outbreak in Serbia. Epidemiological monitoring of measles was strengthened on October 9, 2017 (Institute of Public Health of Serbia, n.d.), making it the official start of the epidemic. Online sources were chosen over traditional 
media because of their rising importance in health and vaccine information seeking behavior (e.g., UNICEF Serbia, 2018). Countries other than the United States are usually underrepresented in health communication research (Catalan-Matamoros et al., 2019; Kim et al., 2010). This study, thus, further contributes to the field by focusing on a country that is neither an English-speaking country nor a high-income economy.

\section{Immunization in Serbia}

The childhood immunization program in Serbia is delivered free of charge for mandatory vaccines, as enforced by law (Official Gazette of RS No. 15/2016, 88/2017). Similarly to a number of post-communist countries (Costa-Font et al., 2021), after introduction of mandatory immunizations in the second half of the twentieth century and a period of low incidence of immuno-preventive diseases, in the last decade Serbia has seen a drop in pediatric vaccine coverage. Despite it being mandatory, a trend of untimely and delayed measles-mumps-rubella (MMR) vaccinations has been observed (Institute of Public Health of Serbia, 2016, 2018). There was an increase from 11 measles cases in 2016 to 721 and 5,076 in 2017 and 2018, respectively (WHO Immunization Data portal, 2021). MCV1 coverage was 81\% in 2016 and $85 \%$ in 2017, while MCV2 coverage was around 91\% in those years (Institute of Public Health of Serbia, 2016, 2018). Regional coverages of the target population were as low as 65\% (Belgrade) in 2016 and $60 \%$ (Nišava) in 2017. Following the measles outbreak, this trend has been reversed. In 2018, MCV1 coverage was 93.4\% (Institute of Public Health of Serbia, 2019). 


\section{Method}

\section{Identification of Online News Stories}

We first set out to identify the highest-trafficked news websites in Serbia. We did not consider investigative journalism websites, news aggregators or magazines. Combining traffic rank data provided by Gemius Audience (rating.gemius.com) - for August 2017 through June 2018 - and Alexa (www.alexa.com) - viewed December 20, 2018 - we chose nine highest trafficked news websites. All websites are in Serbian and focus on national rather than regional or local news; further details can be found in Table 1.

Web search was conducted via Google.rs (the Serbian version of the search engine) between December 2018 and February 2019. We used the terms "vaccine" and "vaccination" in Serbian (vakcina OR vakcinacija), including "site:" in the query, which restricted the search to one website. The date range was additionally customized. The search was conducted using default modes "Sort by relevance" and "All results". Ten results per page were shown. We identified relevant news stories among the first two pages of results for each of the nine websites. We carried out the search for the period between July 1 and December 31,2017 . The decision to limit the search to the first two pages was made in advance to ensure that a maximum of 360 news stories could be sampled in total.

The news story referred to content grouped around one headline. Apart from news reports, we also included opinion pieces, blog posts, editorials, and interviews. We discarded all news stories with predominantly video or audio content as well as any duplicate news stories. A news story became part of the sample if it mentioned human vaccines or vaccination. 
Table 1

Summary of News Websites With the Number of News Stories and Vaccination-Rate Mentions

\begin{tabular}{|c|c|c|c|}
\hline $\begin{array}{l}\text { Website name; } \\
\text { Link }\end{array}$ & Coverage; Type; Readership; Owner & $\begin{array}{c}\text { Number of } \\
\text { news stories }(\%)\end{array}$ & $\begin{array}{c}\text { Number of } \\
\text { vaccination-rate } \\
\text { mentions }(\%)\end{array}$ \\
\hline $\begin{array}{l}\text { Blic; } \\
\text { Www.blic.rs }\end{array}$ & $\begin{array}{l}\text { National coverage; Traditional media's (print) website; } \\
\text { General readership; Privately owned }\end{array}$ & $32(20.00 \%)$ & $112(33.04 \%)$ \\
\hline $\begin{array}{l}\text { Kurir.rs; } \\
\text { www.kurir.rs }\end{array}$ & $\begin{array}{l}\text { National coverage; Traditional media's (print) website; } \\
\text { General readership; Privately owned }\end{array}$ & $21(13.13 \%)$ & $19(5.60 \%)$ \\
\hline $\begin{array}{l}\text { B92 Net; } \\
\text { www.b92.net }\end{array}$ & $\begin{array}{l}\text { National coverage; Traditional media's (television) } \\
\text { website; General readership; Privately owned }\end{array}$ & $11(6.88 \%)$ & $33(9.73 \%)$ \\
\hline $\begin{array}{l}\text { Espreso; } \\
\text { www.espreso.rs }\end{array}$ & $\begin{array}{l}\text { National coverage; News and politics/current affairs } \\
\text { website; General readership; Privately owned }\end{array}$ & $12(7.50 \%)$ & $17(5.01 \%)$ \\
\hline $\begin{array}{l}\text { Novosti.rs; } \\
\text { www.novosti.rs }\end{array}$ & $\begin{array}{l}\text { National coverage; News and politics/current affairs } \\
\text { website; General readership; Privately owned }\end{array}$ & $25(15.63 \%)$ & $60(17.70 \%)$ \\
\hline $\begin{array}{l}\text { Srbija Danas; } \\
\text { www.srbijadanas.com }\end{array}$ & $\begin{array}{l}\text { National coverage; News and politics/current affairs } \\
\text { website; General readership; Privately owned }\end{array}$ & $8(5.00 \%)$ & $22(6.49 \%)$ \\
\hline $\begin{array}{l}\text { Alo.rs; } \\
\text { www.alo.rs }\end{array}$ & $\begin{array}{l}\text { National coverage; Traditional media's (print) website; } \\
\text { General readership; Privately owned }\end{array}$ & $12(7.50 \%)$ & $7(2.06 \%)$ \\
\hline $\begin{array}{l}\text { N1 info; } \\
\text { rs.n1info.com }\end{array}$ & $\begin{array}{l}\text { National coverage; Traditional media's (television) } \\
\text { website; General readership; Privately owned }\end{array}$ & $18(11.25 \%)$ & $34(10.03 \%)$ \\
\hline $\begin{array}{l}\text { Telegraf.rs; } \\
\text { www.telegraf.rs }\end{array}$ & $\begin{array}{l}\text { National coverage; News and politics/current affairs } \\
\text { website; General readership; Privately owned }\end{array}$ & $21(13.13 \%)$ & $35(10.32 \%)$ \\
\hline Total & & $160(100 \%)$ & $339(100 \%)$ \\
\hline
\end{tabular}

Note. Coverage, type, and ownership information for all websites except for N1 info was taken from the https://onlajnmediji.rs/

database (Last accessed June 7, 2022). 
Following these format and topic requirements, we extracted 180 news stories. Twenty news stories were then removed. The search and identification was done manually by the first author. The final sample consisted of 160 news stories (Table 1). The list of discarded stories, with reasons, and PDFs of included news stories are available at https://osf.io/zwcey.

\section{Content Analysis}

The authors developed the initial codes and categories, which the first author expanded and revised by reading the first 68 extracted news stories. The first author then used the final coding scheme to perform content analysis of all included news stories. The present manuscript reports a part of that content analysis. The final coding scheme in English is available at $\underline{\text { https://osf.io/fsjen. }}$

We coded the headline, the lead, and the main text, including subheadlines and image titles. We did not code links, trails and previews of other news stories, embedded content, comments, and tags. There were two content analysis units - the news story as a whole and every mention of a vaccination rate within the news story.

\section{News Story-Level Content Analysis}

We coded whether the text of the news story mentioned vaccination rates at least once. Vaccination rate was defined as the number or percentage of people who are either vaccinated or not vaccinated. Rates could also be expressed verbally (e.g., "the majority of people have been vaccinated"). Mentions of the general interest in vaccination, vaccine hesitancy and resistance were not coded as vaccination rate.

We coded how many times the text of the news story mentioned vaccination rates. As long as the vaccination-rate information appeared in separate dependent or independent clauses, 
it was counted as a separate mention. Vaccination-rate information presented via infographics did not count towards this. However, we did code whether the news story used infographics (e.g., charts, number graphics, population diagrams, maps, data tables) to present any vaccination rates. This variable was used as a proxy for the amount of prominence given to vaccination rates.

Next, we coded whether the news story mentioned the term "herd immunity" or “collective immunity" (imunitet krda, kolektivni imunitet). To be considered complete, the definition had to (a) refer to the need to reach the herd-immunity threshold; and (b) mention at least one of the following two main consequences of reaching the herd-immunity threshold: that the pathogen can no longer be transmitted and/or that everyone in the population is protected (Fine et al., 2011). Examples of complete definitions include "if enough people are vaccinated, the disease cannot spread and no new people can be infected" or "when vaccination coverage reaches a certain threshold, the epidemic is stopped". A definition could not include imprecise statements, such as "corrupting herd immunity risks a higher chance of an outbreak" or "the vaccinated build and sustain herd immunity", without further explanation. Finally, we coded whether the news story mentioned the exact numerical value of the herd-immunity threshold (e.g., $95 \%$ for measles).

\section{Vaccination Rate-Level Content Analysis}

There was a total of 339 vaccination-rate mentions in the selected news stories (Table 1). Each vaccination-rate mention was coded separately for a number of features. We coded:

- whether the vaccination rate appeared in the first headline on the page (to assess its prominence);

- whether the vaccination-rate information was sourced and who the source was; 
- the vaccine the rate referred to and whether it was explicitly mentioned that the rate referred to any dose following the first one (e.g., second dose, revaccination, booster);

- the population and territory the vaccination rate referred to;

- in which (non-)numerical format the vaccination rate was presented and whether the exact numerical value of the vaccination rate was provided;

- whether the vaccination rate was provided as a static or dynamic descriptive norm;

- whether the vaccination rate was framed as the proportion of those vaccinated or those not vaccinated; and

- whether the vaccination rate was framed in a positive (e.g., as high as, increasing, above a satisfactory level, good), negative (e.g., only, decreasing, below a satisfactory level, poor) or neutral way. The valence could have also been deduced from the immediate context surrounding the vaccination-rate mention (e.g., the vaccination rate was presented as an approval or encouragement or as a warning or intimidation).

\section{Inter-Coder Reliability Test}

An independent coder was trained on the coding scheme and coded a subsample consisting of randomly chosen $20 \%$ of the included news stories $(n=32)$, containing $64(18.9 \%)$ out of a total of 339 vaccination-rate mentions. We computed Krippendorff's alpha $(\alpha)$ - as well as percent agreement because some variables were skewed or without variation in the data using the irrCAC $\}$ package (Gwet, 2019) in R 4.1.2 (R Core Team, 2020) (Table 2). Average inter-coder reliability for the variables reported in this paper was $\alpha=.89$. Out of 16 variables, eight obtained reliability .91-1.00, four .81-.87, and four obtained reliability .70-.79. 
Table 2

Inter-Coder Reliability Coefficients for All of the Reported Variables

\begin{tabular}{|c|c|c|}
\hline Variable & $\begin{array}{c}\text { Percent } \\
\text { Agreement }\end{array}$ & $\begin{array}{l}\text { Krippendorff's } \\
\text { Alpha }\end{array}$ \\
\hline \multicolumn{3}{|l|}{ 1. News Story-Level Variables } \\
\hline Rate mentioned (yes, no) & $91 \%$ & .81 \\
\hline Number of mentioned rates & $82 \%$ & .75 \\
\hline Infographics used (yes, no) & $100 \%$ & 1.00 \\
\hline Herd immunity mentioned (yes, no) & $100 \%$ & 1.00 \\
\hline Herd immunity explained (yes, no) & $97 \%$ & .79 \\
\hline Critical herd immunity mentioned (yes, no) & $100 \%$ & 1.00 \\
\hline \multicolumn{3}{|l|}{ 2. Vaccination Rate-Level Variables } \\
\hline Appears in the headline (yes, no) & $100 \%$ & NA \\
\hline Source specified (yes, no) & $85 \%$ & .70 \\
\hline Source type ${ }^{a}$ & $100 \%$ & 1.00 \\
\hline Vaccine & $94 \%$ & .87 \\
\hline Revaccination/second dose (yes, no) & $100 \%$ & 1.00 \\
\hline Reference group - population & $93 \%$ & .74 \\
\hline Reference group - territory ${ }^{\text {a }}$ & $89 \%$ & .85 \\
\hline Format (absolute/relative number, frequency, descriptive) & $96 \%$ & .94 \\
\hline Trend (static, dynamic) & $96 \%$ & .91 \\
\hline Frame (proportion of vaccinated/unvaccinated) & $100 \%$ & 1.00 \\
\hline Frame (positive, negative, neutral) & $94 \%$ & .86 \\
\hline \multicolumn{3}{|c|}{ Note. NA indicates that Krippendorff's alpha could not be calculated because the variable had no } \\
\hline \multicolumn{3}{|c|}{${ }^{a}$ Estimates were calculated after the initial categories were collapsed into fewer, broader } \\
\hline
\end{tabular}




\section{Results}

We carried out a descriptive analysis of the collected data. Datasets are openly available at https://osf.io/zxhtr.

\section{Prevalence and Prominence of Vaccination Rates}

Over half of the selected news stories $(53.75 \%, 86 / 160)$ mentioned vaccination rates at least once. There were, on average, 2.1 vaccination-rate mentions per news story, with this number ranging from 1 to 26 . A total of $1.77 \%$ (6/339) of vaccination-rate mentions appeared in the headline; that is, $3.75 \%(6 / 160)$ of news stories had headlines featuring this information. A total of $5.00 \%(8 / 160)$ of news stories used infographics to communicate vaccination rates.

\section{Source of Vaccination Rates}

The main sources of vaccination-rate information were domestic medical and public health institutions and experts (Table 3). Institutes for public health, community health centers (dom zdravlja), and named epidemiologists were a common source type $(30.68 \%, 104 / 339$, $12.98 \%, 44 / 339$, and $9.14 \%, 31 / 339$, respectively). News stories sometimes $(8.85 \%, 30 / 339)$ cited generic experts and expert institutions (e.g., scientists, pediatricians). Other sources are listed in Table 3. About a quarter of vaccination rates $(28.91 \%, 98 / 339)$ were reported without specifying the source. 


\section{Table 3}

Frequency of Vaccination-Rate Mentions $(N=339)$ Coming From Different Sources

\begin{tabular}{|c|c|c|}
\hline & $\begin{array}{c}\text { Number of } \\
\text { vaccination-rate } \\
\text { mentions }\end{array}$ & $\%$ \\
\hline Institute of Public Health of Serbia Dr. Milan Jovanović Batut & 49 & $14.45 \%$ \\
\hline Community health centers & 44 & $12.98 \%$ \\
\hline Epidemiologists, mentioned by name & 31 & $9.14 \%$ \\
\hline Local institutes for public health (other) & 31 & $9.14 \%$ \\
\hline Generic experts and expert institutions & 30 & $8.85 \%$ \\
\hline City Institute for Public Health Belgrade & 24 & $7.08 \%$ \\
\hline Healthcare professionals, mentioned by name (other) & 8 & $2.36 \%$ \\
\hline Associations of healthcare workers & 7 & $2.06 \%$ \\
\hline Associations of citizens and parents & 6 & $1.77 \%$ \\
\hline Nursery, preschool, elementary, high school & 3 & $0.88 \%$ \\
\hline Medical faculties & 2 & $0.59 \%$ \\
\hline Clinic for Infectious and Tropical Diseases & 1 & $0.29 \%$ \\
\hline Electronic Immunization Registry & 1 & $0.29 \%$ \\
\hline Ministry of Health & 1 & $0.29 \%$ \\
\hline UNICEF & 1 & $0.29 \%$ \\
\hline World Health Organization & 1 & $0.29 \%$ \\
\hline "Unnamed" source & 1 & $0.29 \%$ \\
\hline No source cited & 98 & $28.91 \%$ \\
\hline
\end{tabular}

Note. Individuals/organizations mentioned as sources of vaccination-rate information by the news stories and the number/proportion of vaccination-rate mentions associated with them. 


\section{Types of Vaccines and Revaccinations}

The majority of the vaccination rates $(77.29 \%, 262 / 339)$ referred to the MMR vaccine, whereas $13.27 \%(45 / 339)$ referred to vaccinations in general. The other vaccines that the rates referred to were against: diphtheria, tetanus, whooping cough, polio, and Haemophilus influenzae type b $(3.24 \%, 11 / 339)$, hepatitis b $(2.36 \%, 8 / 339)$, flu $(1.18 \%, 4 / 339)$, polio $(1.18 \%$, 4/339), tuberculosis (BCG vaccine, 0.59\%, 2/339), pneumococcal infections $(0.29 \%, 1 / 339)$; in 2 $(0.59 \%)$ cases vaccine type could not be determined. A total of $5.90 \%$ (20/339) of vaccinationrate mentions explicitly referred to a dose that is not the first dose of the vaccine.

\section{Reference Groups}

The majority of the vaccination rates $(78.47 \%, 266 / 339)$ referred to children aged 0-14 years. This should not be surprising given that most of the immunization rates referred to the MMR and other pediatric vaccines in Serbia. Different subpopulations of children are specified in Table 4. Vaccination rates among the vulnerable were almost never mentioned (in $1.18 \%$ or $4 / 339$ of cases). A total of $2.65 \%$ (9/339) of vaccination-rate mentions referred to the general population (e.g., people, persons, citizens).

Most of the vaccination rates were reported for the country of Serbia as a whole $(35.10 \%$, $119 / 339)$ as well as at the city- or town-level (31.56\%, 107/339). Some cities in Serbia are divided into municipalities (opštine) - vaccination rates were reported at this level in $11.80 \%$ (40/339) of cases. Table 4 lists all of the territories that the vaccination rates referred to. 


\section{Table 4}

Frequency of Vaccination-Rate Mentions $(N=339)$ Across Different Populations and Territories

\begin{tabular}{cc}
\hline Number of \\
vaccination-rate \\
mentions
\end{tabular}

1. Population

Children

Children 0-14 y.o. (age / school status not specified)

Children 1-7 y.o. (school status not specified)

Elementary school (or to be enrolled) (7-14 y.o.)

Children 0-6 months (newborns, babies)

8

$2.36 \%$

Nursery / preschool (or to be enrolled)

Vulnerable

People aged 60 and over

Pregnant women

Vulnerable (in general or combination of subpopulations)

Other

General population

Undetermined / not mentioned
$17.70 \%$

2. Territory

Serbia

Country as a whole

City / town

City municipality (opština)

Central Serbia, Serbian enclaves in Kosovo, Vojvodina

Country district (okrug)

Nursery, preschool, elementary, high school
$35.10 \%$

$31.56 \%$

$11.80 \%$

$6.19 \%$

$0.88 \%$

$0.88 \%$ 
Table 4 Continued

\begin{tabular}{lcc}
\hline & $\begin{array}{c}\text { Number of } \\
\text { vaccination-rate } \\
\text { mentions }\end{array}$ & $\%$ \\
\hline Other & 18 & $5.31 \%$ \\
Balkans (country, country region, city / town) & 18 & $5.31 \%$ \\
Europe (continent, country in Europe / European Union) & 5 & $1.47 \%$ \\
Whole world & 4 & $1.18 \%$ \\
Other countries & 1 & $0.29 \%$ \\
Undetermined / not mentioned & 5
\end{tabular}

Note. Reference groups in terms of the population and territory and the number/proportion of vaccination-rate mentions referring to different groups. The population and the territory groups were coded separately.

\section{Numerical Versus Verbal Presentation}

A total of $57.82 \%(196 / 339)$ of vaccination rates were communicated numerically. Most of the vaccination rates $(50.44 \%, 171 / 339)$ were presented in relative terms, such as percentages and fractions (e.g., "80\%”, “every second”, “third of”). Other numerical formats included absolute counts (e.g., "9,000”) (6.78\%, 23/339) and frequency statements (e.g., "5,496 out of $20,768 ”)(0.59 \%, 2 / 339)$. The rest of the vaccination rates $(143 / 339,42.18 \%)$ were communicated verbally, without the numerical value. Descriptive terms used were, for example, "most of the population", "a drop in", "low", "weak", "below an acceptable level".

Since the same vaccination rate could have been mentioned both in a numerical and verbal format within the same news story, we additionally counted the number of news stories that provided no numerical values, either via text or infographics. A total of $26.74 \%(23 / 86)$ of news stories reporting vaccination rates used only descriptive terms to do so. 


\section{Static Versus Dynamic Norms}

The majority of vaccination rates $(71.09 \%, 241 / 339)$ were communicated as static norms. The remaining vaccination rates $(28.91 \%, 98 / 339)$ were communicated as dynamic norms. News stories reported that "more parents are vaccinating their children", "immunization levels have risen by $10 \% "$ " "the rates are declining", "this year's coverage will be smaller if the trend stays".

\section{Framing as the Proportion of Vaccinated Versus Unvaccinated}

Almost all vaccination rates were presented as the proportion of vaccinated individuals $(90.27 \%, 306 / 339)$, as opposed to the proportion of non-vaccinated individuals $(9.73 \%$, 33/339). A news story could report that " $60 \%$ of children are vaccinated" versus that " $40 \%$ of children are not vaccinated".

\section{Positive, Negative or Neutral Frame}

While we observed both positive $(18.29 \%, 62 / 339)$ and neutral $(10.32 \%, 35 / 339)$ vaccination-rate mentions, the majority of mentions were coded as being negative $(71.39 \%$, 242/339). News stories, for example, reported that "fewer parents are vaccinating their children", "the coverage is very low, almost $40 \%$ of children haven't received the vaccine", "only $50 \%$ vaccinated", "every second child not vaccinated, epidemic just a matter of time".

The proportion of negative frames remained similar regardless of the way in which the rates were communicated and of the vaccine they referred to (Figure 1), suggesting that the finding is robust. Negatively valenced attribute frames were identified by calculating the proportion of negative mentions only among the vaccination rates that were communicated numerically; the prevalence of such negative frames remained high $(66.33 \%, 130 / 196)$. Vaccination rates that were communicated only verbally were also often presented in a negative 
way $(78.32 \%, 112 / 143)$. Furthermore, both static and dynamic vaccination rates were presented mostly in a negative way $(72.61 \%, 175 / 241$ and $68.37 \%, 67 / 98$, respectively). Finally, $77.10 \%$ (202/262) of MMR vaccination rates and 51.95\% (40/77) of the rates for all other vaccines were negatively framed. 


\section{Figure 1}

The Proportion of Positive, Neutral, and Negative Frames of Vaccination Rates

a

$$
\text { Vaccination rate framing } \square \text { positive } \square \text { neutral } \square \text { negative }
$$

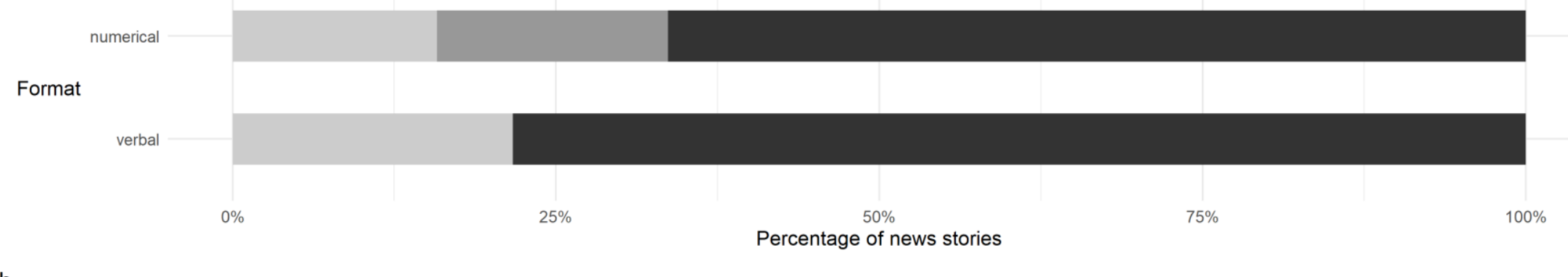

b

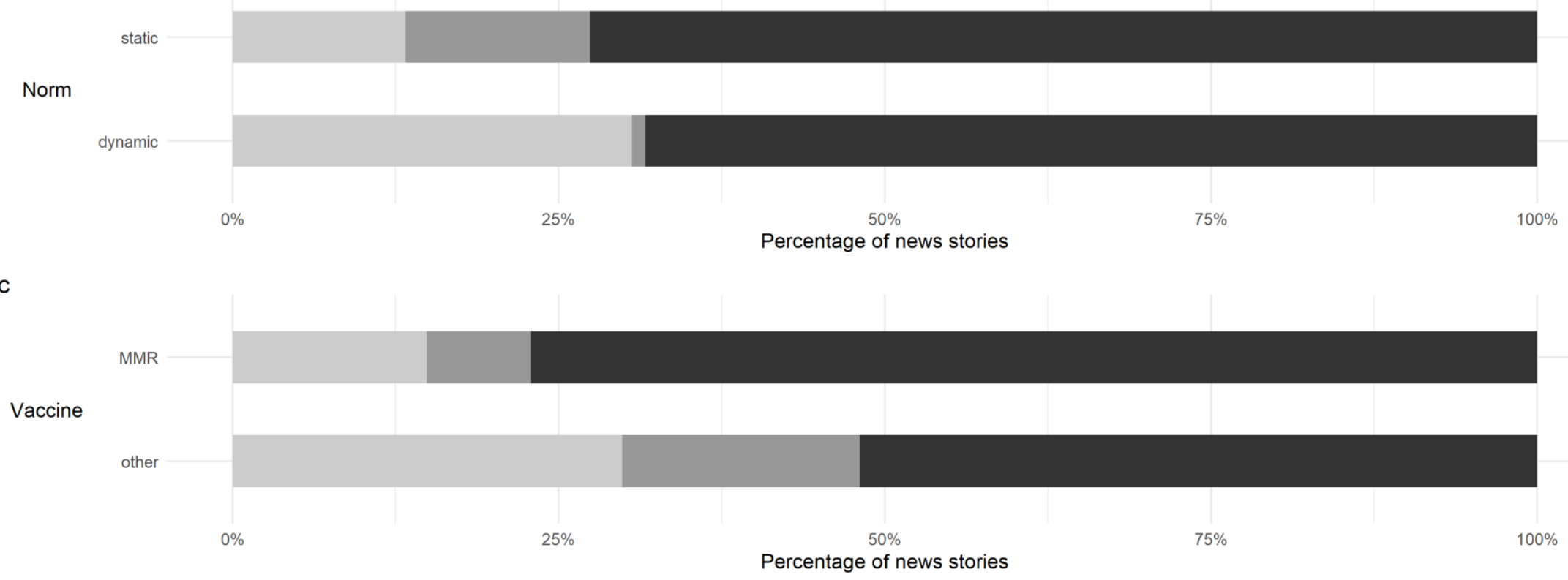

Note. This figure shows how many vaccination rates (in percentages) were framed positively, neutrally or negatively depending on (a) their format (numerical, verbal); (b) norms they communicated (static, dynamic); and (c) the vaccine they referred to (MMR, other). Figure created using \{ggplot2\} (Wickham, 2016) in R 4.1.2 (R Core Team, 2020). 


\section{Herd-Immunity Communication}

Terms referring to herd immunity were mentioned in $20.00 \%(32 / 160)$ of news stories. A total of $9.38 \%(15 / 160)$ of news stories gave a complete and precise definition of the herdimmunity effect, some naming it and some not. Out of the stories mentioning the term, $34.38 \%$ $(11 / 32)$ defined the effect of herd immunity. Almost a quarter $(23.13 \%, 37 / 160)$ of news stories provided the exact numerical value of the herd-immunity threshold.

\section{Discussion}

This content analysis explored online news coverage of vaccination rates and herd immunity in Serbia, around the start of the 2017 measles epidemic. Perhaps under the impression that such messages can be fear-inducing and thus mobilizing, the online news media often signaled low vaccination rates. This finding is in line with a content analysis of Australian newsprint media from twenty years ago (Leask \& Chapman, 2002). The majority of vaccination rates, including seemingly objective vaccination rate numbers and changes in vaccination rates over time, were presented in a negative light by applying simple attribute frames (e.g., "only 50\% vaccinated", "fewer parents vaccinating their children"). Rather than being mobilizing, framing vaccination rates negatively could discourage vaccination by activating a powerful negative descriptive norm - "many people are not getting vaccinated" (e.g., Belle \& Cantarelli, 2021; Milkman et al., 2022; Palm et al., 2021; Romley et al., 2016). Whenever possible, news stories should, therefore, consider framing vaccination rates positively (e.g., "already $60 \%$ vaccinated") rather than negatively (e.g., "only $60 \%$ vaccinated"), or not framing them at all. Framing would make the positive norms more salient and thus more likely to shape health behavior (Cialdini et al., 1990). 
While the majority of vaccination rates came from medical and public health expert sources, no source was provided for over a quarter of vaccination rates. Most of the vaccination rates were reported on the country- or city/town-level. Vaccination rates were less frequently reported for city municipalities, even though these statistics were freely available on the website of the Institute of Public Health of Serbia, which was the most frequent source of information in the news stories. While MMR vaccination coverage was above $70-80 \%$ in most of the Serbian city municipalities during the measles outbreak, some city municipalities had coverage below $70 \%$ (Institute of Public Health of Serbia, 2018). Reporting this could have been beneficial in order to highlight the limits of the free-riding strategy (Meszaros et al., 1996). Furthermore, when individuals feel identified with the reference group, normative information is generally more likely to be effective (for a review, see Tankard \& Paluck, 2016). The news media should, therefore, consider reporting more specific reference groups for the vaccination rates, not only in terms of geographical residence but also in terms of age, school status or vulnerability level.

We found that herd-immunity communication remains underutilized in the media (Leask \& Chapman, 2002) - around 9\% of online news stories explained the benefits of herd immunity through vaccination, while around a quarter provided the value of the vaccination rate that stops the disease from spreading. Communicating social benefits of herd immunity has been shown to improve vaccination intentions (e.g., Betsch et al., 2017). There have been, however, fewer studies that tested how communicating the herd-immunity threshold would fare at different descriptive norm levels (Lazić et al., 2021). For example, if people learn that the vaccination rate is close to the threshold, this could lead them to expect that their vaccination choice could make a difference; in contrast, if they learn that the vaccination rate is far below the threshold, they 
may conclude that their individual contribution to herd immunity will not be sufficient (see Moussaoui \& Desrichard, 2017).

\section{Strengths, Limitations, and Recommendations for Future Studies}

This study represents one of few analyses of news media framing of vaccination rates. In contrast to most previous studies, we attempted to conceptualize negativity mostly irrespective of issue-specific, anti-vaccine rhetoric. This allowed us to provide guidelines for a routine, everyday aspect of public vaccine communication, while identifying some commonly-used communication strategies that have the potential to backfire. We developed a detailed coding scheme, which can be used in future studies of public health communication and applied to other influential events, such as the COVID-19 pandemic.

That said, it should be noted that the generalizability of this study's findings could be limited by some characteristics of the analyzed news stories. First, all news stories appeared online and only news story text was analyzed. Shortcomings we identified may not be reflective of shortcomings in vaccination-rate communication in other formats (e.g., traditional print media or online video news stories). Secondly, the findings might be context specific as they were sampled from a 6-month period around the time of the 2017 measles outbreak in Serbia.

Understanding the full influence of news media will require studying not only descriptive but also injunctive normative messages (about vaccination attitudes, opinions, recommendations, etc.). Future studies could explore specific dimensions of negativity in vaccination-rate communication, such as pessimism or negative tone towards certain actors (e.g., putting blame on parents). To be able to study the construction of the vaccination discourse in local media and 
connect it with the broader socio-cultural context, future studies could apply more qualitative techniques (such as discourse analysis).

\section{Conclusion}

Through a content analysis of online news stories relating to vaccination, we identified ways in which vaccination rates were presented and framed around the start of the 2017 measles outbreak in Serbia. Even routine communication of vaccination rates was biased through negative frames (e.g., "only 50\% vaccinated") and imprecise descriptions (e.g., "the coverage is low"). Furthermore, the news stories rarely explained the benefits of achieving herd immunity through vaccination. We explain how some of the common strategies, such as lamenting low vaccination rates, may backfire. While this study provides some initial recommendations for mitigating these issues, more studies are needed to evaluate how and under what conditions normative messages and frames influence vaccine uptake. 


\section{References}

Akl, E. A., Oxman, A. D., Herrin, J., Vist, G. E., Terrenato, I., Sperati, F., Costiniuk, C., Blank, D., \& Schünemann, H. (2011). Framing of health information messages. The Cochrane Database of Systematic Reviews, 12, CD006777. https://doi.org/10.1002/14651858.CD006777.pub2

Allen, J. D., Mohllajee, A. P., Shelton, R. C., Othus, M. K. D., Fontenot, H. B., \& Hanna, R. (2009). Stage of adoption of the human papillomavirus vaccine among college women. Preventive Medicine, 48(5), 420-425. https://doi.org/10.1016/j.ypmed.2008.12.005

Altay, S., \& Mercier, H. (2020). Framing messages for vaccination supporters. Journal of Experimental Psychology: Applied, 26(4), 567-578. https://doi.org/10.1037/xap0000271

Baumeister, R. F., Bratslavsky, E., Finkenauer, C., \& Vohs, K. D. (2001). Bad is stronger than good. Review of General Psychology, 5(4), 323-370. https://doi.org/10.1037/1089$\underline{2680.5 .4 .323}$

Behavioural Insights Team. (2012). Applying behavioural insights to reduce fraud, error, and debt. https://www.gov.uk/government/publications/fraud-error-and-debt-behaviouralinsights-team-paper

Belle, N., \& Cantarelli, P. (2021). Nudging public employees through descriptive social norms in healthcare organizations. Public Administration Review, 81(4), 589-598. https://doi.org/10.1111/puar.13353

Betsch, C., Böhm, R., Korn, L., \& Holtmann, C. (2017). On the benefits of explaining herd immunity in vaccine advocacy. Nature Human Behaviour, 1(3), 0056. https://doi.org/10.1038/s41562-017-0056 
Bigman, C. A., Cappella, J. N., \& Hornik, R. C. (2010). Effective or ineffective: Attribute framing and the human papillomavirus (HPV) vaccine. Patient Education and Counseling, 81, S70-S76. https://doi.org/10.1016/j.pec.2010.08.014

Böhm, R., Betsch, C., \& Korn, L. (2016). Selfish-rational non-vaccination: Experimental evidence from an interactive vaccination game. Journal of Economic Behavior \& Organization, 131, 183-195. https://doi.org/10.1016/j.jebo.2015.11.008

Bradley, S. D., Angelini, J. R., \& Lee, S. (2007). Psychophysiological and memory effects of negative political ads: Aversive, arousing, and well remembered. Journal of Advertising, 36(4), 115-127. https://doi.org/10.2753/JOA0091-3367360409

Catalan-Matamoros, D., Santamaria-Ochoa, C.-D., \& Peñafiel-Saiz, C. (2019). Message analyses about vaccines in the print press, television and radio: Characteristics and gaps in previous research. Journal of Communication in Healthcare, 12(2), 86-101. https://doi.org/10.1080/17538068.2019.1614377

Chong, D., \& Druckman, J. N. (2007). Framing theory. Annual Review of Political Science, 10(1), 103-126. https://doi.org/10.1146/annurev.polisci.10.072805.103054

Cialdini, R. B. (2003). Crafting normative messages to protect the environment. Current Directions in Psychological Science, 12(4), 105-109. https://doi.org/10.1111/1467$\underline{8721.01242}$

Cialdini, R. B., Demaine, L. J., Sagarin, B. J., Barrett, D. W., Rhoads, K., \& Winter, P. L. (2006). Managing social norms for persuasive impact. Social Influence, 1(1), 3-15. https://doi.org/10.1080/15534510500181459 
Cialdini, R. B., Reno, R. R., \& Kallgren, C. A. (1990). A focus theory of normative conduct: Recycling the concept of norms to reduce littering in public places. Journal of Personality and Social Psychology, 58(6), 1015-1026. https://doi.org/10.1037/0022-3514.58.6.1015

Clayton, K., Finley, C., Flynn, D. J., Graves, M., \& Nyhan, B. (2021). Evaluating the effects of vaccine messaging on immunization intentions and behavior: Evidence from two randomized controlled trials in Vermont. Vaccine. https://doi.org/10.1016/j.vaccine.2021.08.047

Costa-Font, J., Garcia-Hombrados, J., \& Nicińska, A. (2021). The institutional origins of vaccines distrust: Evidence from former-communist countries. Preprint retrieved from Research Square. https://doi.org/10.21203/rs.3.rs-400867/v1

Dannetun, E., Tegnell, A., Hermansson, G., \& Giesecke, J. (2005). Parents’ reported reasons for avoiding MMR vaccination. Scandinavian Journal of Primary Health Care, 23(3), 149153. https://doi.org/10.1080/02813430510031306

Druckman, J. N. (2001). The implications of framing effects for citizen competence. Political Behavior, 23(3), 225-256. https://doi.org/10.1023/A:1015006907312

Evans, M., Stoddart, H., Condon, L., Freeman, E., Grizzell, M., \& Mullen, R. (2001). Parents’ perspectives on the MMR immunisation: A focus group study. The British Journal of General Practice: The Journal of the Royal College of General Practitioners, 51(472), 904-910. http://www.ncbi.nlm.nih.gov/pubmed/11761204

Feuerriegel, S., Robertson, C., Pröllochs, N., Schwarzenegger, K., Pärnamets, P., \& Van Bavel, J. J.. (2022). Negativity drives online news consumption [Registered Report Stage 1 Protocol] (Version1). figshare. https://doi.org/10.6084/m9.figshare.19657452.v1 
Fine, P., Eames, K., \& Heymann, D. L. (2011). “Herd immunity”: A rough guide. Clinical Infectious Diseases, 52(7), 911-916. https://doi.org/10.1093/cid/cir007

Freeman, D., Loe, B. S., Yu, L.-M., Freeman, J., Chadwick, A., Vaccari, C., Shanyinde, M., Harris, V., Waite, F., Rosebrock, L., Petit, A., Vanderslott, S., Lewandowsky, S., Larkin, M., Innocenti, S., Pollard, A. J., McShane, H., \& Lambe, S. (2021). Effects of different types of written vaccination information on COVID-19 vaccine hesitancy in the UK (OCEANS-III): A single-blind, parallel-group, randomised controlled trial. The Lancet Public Health, 6(6), e416-e427. https://doi.org/10.1016/S2468-2667(21)00096-7

Gangarosa, E., Galazka, A., Wolfe, C., Phillips, L., Miller, E., Chen, R., \& Gangarosa, R. (1998). Impact of anti-vaccine movements on pertussis control: the untold story. The Lancet, 351(9099), 356-361. https://doi.org/10.1016/S0140-6736(97)04334-1

Gerber, A. S., \& Rogers, T. (2009). Descriptive social norms and motivation to vote: Everybody's voting and so should you. The Journal of Politics, 71(1), 178-191. https://doi.org/10.1017/S0022381608090117

Goldstein, N. J., Cialdini, R. B., \& Griskevicius, V. (2008). A room with a viewpoint: Using social norms to motivate environmental conservation in hotels. Journal of Consumer Research, 35(3), 472-482. https://doi.org/10.1086/586910

Graupensperger, S., Abdallah, D. A., \& Lee, C. M. (2021). Social norms and vaccine uptake: College students' COVID vaccination intentions, attitudes, and estimated peer norms and comparisons with influenza vaccine. Vaccine, 39(15), 2060-2067. https://doi.org/10.1016/j.vaccine.2021.03.018 
Guillaume, L. R., \& Bath, P. A. (2004). The impact of health scares on parents' information needs and preferred information sources: A case study of the MMR vaccine scare. Health Informatics Journal, 10(1), 5-22. https://doi.org/10.1177/1460458204040664

Gwet, K. L. (2019). irrCAC: Computing chance-corrected agreement coefficients (CAC). (Version 1.0). https://cran.r-project.org/package=irrCAC

Hershey, J. C., Asch, D. A., Thumasathit, T., Meszaros, J., \& Waters, V. V. (1994). The roles of altruism, free riding, and bandwagoning in vaccination decisions. Organizational Behavior and Human Decision Processes, 59(2), 177-187. https://doi.org/10.1006/obhd.1994.1055

Ibuka, Y., Li, M., Vietri, J., Chapman, G. B., \& Galvani, A. P. (2014). Free-riding behavior in vaccination decisions: An experimental study. PLoS ONE, 9(1), e87164. https://doi.org/10.1371/journal.pone.0087164

Institute of Public Health of Serbia. (n.d.). Aktuelna epidemiološka situacija malih boginja (morbila) u Republici Srbiji [The current epidemiological situation of measles in the Republic of Serbia]. https://www.batut.org.rs/index.php?content=1629

Institute of Public Health of Serbia. (2016). Izveštaj o sprovedenoj imunizaciji na teritoriji Republike Srbije u 2016. godini [Report on conducted immunization on the territory of the Republic of Serbia in 2016]. https://www.batut.org.rs/download/izvestaji/Godisnji izvestaj imunizacija 2016.pdf

Institute of Public Health of Serbia. (2018). Izveštaj o sprovedenoj imunizaciji na teritoriji Republike Srbije u 2017. godini [Report on conducted immunization on the territory of the Republic of Serbia in 2017]. http://www.batut.org.rs/download/izvestaji/Godisnji izvestaj imunizacija 2017.pdf 
Institute of Public Health of Serbia. (2019). Izveštaj o sprovedenoj imunizaciji na teritoriji Republike Srbije u 2018. godini [Report on conducted immunization on the territory of the Republic of Serbia in 2018]. https://www.batut.org.rs/download/izvestaji/Godisnji imunizacija 2018.pdf

Kelly, B. J., Leader, A. E., Mittermaier, D. J., Hornik, R. C., \& Cappella, J. N. (2009). The HPV vaccine and the media: How has the topic been covered and what are the effects on knowledge about the virus and cervical cancer? Patient Education and Counseling, 77(2), 308-313. https://doi.org/10.1016/j.pec.2009.03.018

Kim, J.-N., Park, S.-C., Yoo, S.-W., \& Shen, H. (2010). Mapping health communication scholarship: Breadth, depth, and agenda of published research in health communication. Health Communication, 25(6-7), 487-503. https://doi.org/10.1080/10410236.2010.507160

Lazić, A., Kalinova, K. N., Packer, J., Pae, R., Petrović, M. B., Popović, D., Sievert, D. E. C., \& Stafford-Johnson, N. (2021). Social nudges for vaccination: How communicating herd behaviour influences vaccination intentions. British Journal of Health Psychology, 26(4), 1219-1237. https://doi.org/10.1111/bjhp.12556

Leader, A. E., Weiner, J. L., Kelly, B. J., Hornik, R. C., \& Cappella, J. N. (2009). Effects of information framing on human papillomavirus vaccination. Journal of Women's Health, 18(2), 225-233. https://doi.org/10.1089/jwh.2007.0711

Leask, J., \& Chapman, S. (2002). 'The cold hard facts' Immunisation and vaccine preventable diseases in Australia's newsprint media 1993-1998. Social Science \& Medicine, 54(3), 445-457. https://doi.org/10.1016/S0277-9536(01)00130-7

Leeper, T. J., \& Slothuus, R. (2020). How the news media persuades: Framing effects and beyond. In E. Suhay, B. Grofman, \& A. H. Trechsel (Eds.), The Oxford handbook of 
electoral persuasion (pp. 150-168). Oxford University Press. https://doi.org/10.1093/oxfordhb/9780190860806.013.4

Levin, I. P., Schneider, S. L., \& Gaeth, G. J. (1998). All frames are not created equal: A typology and critical analysis of framing effects. Organizational Behavior and Human Decision Processes, 76(2), 149-188. https://doi.org/10.1006/obhd.1998.2804

Logan, J., Nederhoff, D., Koch, B., Griffith, B., Wolfson, J., Awan, F. A., \& Basta, N. E. (2018). 'What have you HEARD about the HERD?' Does education about local influenza vaccination coverage and herd immunity affect willingness to vaccinate? Vaccine, 36(28), 4118-4125. https://doi.org/10.1016/j.vaccine.2018.05.037

Ma, K. K. (2006). Influenza vaccinations of young children increased with media coverage in 2003. Pediatrics, 117(2), e157-e163. https://doi.org/10.1542/peds.2005-1079

Mason, B. W., \& Donnelly, P. D. (2000). Impact of a local newspaper campaign on the uptake of the measles mumps and rubella vaccine. Journal of Epidemiology and Community Health, 54(6), 473-474. https://doi.org/10.1136/jech.54.6.473

Meszaros, J. R., Asch, D. A., Baron, J., Hershey, J. C., Kunreuther, H., \& Schwartz-Buzaglo, J. (1996). Cognitive processes and the decisions of some parents to forego pertussis vaccination for their children. Journal of Clinical Epidemiology, 49(6), 697-703. https://doi.org/10.1016/0895-4356(96)00007-8

Milkman, K. L., Gandhi, L., Patel, M. S., Graci, H. N., Gromet, D. M., Ho, H., ... \& Duckworth, A. L. (2022). A 680,000-person megastudy of nudges to encourage vaccination in pharmacies. Proceedings of the National Academy of Sciences, 119(6), e2115126119. https://doi.org/10.1073/pnas.2115126119 
Moehring, A., Collis, A., Garimella, K., Rahimian, M. A., Aral, S., \& Eckles, D. (2021).

Surfacing norms to increase vaccine acceptance. Preprint retrieved from PsyArXiv. https://doi.org/10.31234/osf.io/srv6t

Mortensen, C. R., Neel, R., Cialdini, R. B., Jaeger, C. M., Jacobson, R. P., \& Ringel, M. M. (2019). Trending norms: A lever for encouraging behaviors performed by the minority. Social Psychological and Personality Science, 10(2), 201-210. https://doi.org/10.1177/1948550617734615

Moussaoui, L. S., \& Desrichard, O. (2017). "Being green is worthless if others are not": The effect of descriptive norms on pro-environmental behaviour is mediated by outcome expectancy / "Ser verde no vale de nada si los demás no lo son”: El efecto de las normas descriptivas sobre el comportamiento proambiental está mediado por la expectativa de resultado. Psyecology, 8(3), 267-296. https://doi.org/10.1080/21711976.2017.1359370

Official Gazette of the Republic of Serbia. (n.d.). Pravilnik o imunizaciji i načinu zaštite lekovima [Rulebook on immunization and drug prescription]. No. 88/2017. https://www.paragraf.rs/propisi/pravilnik_o_imunizaciji_i_nacinu_zastite_lekovima.html Official Gazette of the Republic of Serbia. (n.d.). Zakon o zaštiti stanovništva od zaraznih bolesti [Law on protection of population from infectious diseases]. No. 15/2016. https://www.paragraf.rs/propisi/zakon_o_zastiti_stanovnistva_od_zaraznih_bolesti.html

Palm, R., Bolsen, T., \& Kingsland, J. T. (2021). The effect of frames on COVID-19 vaccine resistance. Frontiers in Political Science, 3. https://doi.org/10.3389/fpos.2021.661257

Pfattheicher, S., Petersen, M. B., \& Böhm, R. (2022). Information about herd immunity through vaccination and empathy promote COVID-19 vaccination intentions. Health Psychology, 41(2), 85-93. https://doi.org/10.1037/hea0001096 
R Core Team. (2020). R: A language and environment for statistical computing. R Foundation for Statistical Computing. https://www.r-project.org/

Romley, J., Goutam, P., \& Sood, N. (2016). National survey indicates that individual vaccination decisions respond positively to community vaccination rates. PLOS ONE, 11(11), e0166858. https://doi.org/10.1371/journal.pone.0166858

Rozin, P., \& Royzman, E. B. (2001). Negativity bias, negativity dominance, and contagion. Personality and Social Psychology Review, 5(4), 296-320. https://doi.org/10.1207/S15327957PSPR0504_2

Ryoo, Y., \& Kim, W. (2021). Using descriptive and injunctive norms to encourage COVID-19 social distancing and vaccinations. Health Communication, 1-10. https://doi.org/10.1080/10410236.2021.1973702

Schneider, S. L., Burke, M. D., Solomonson, A. L., \& Laurion, S. K. (2005). Incidental framing effects and associative processes: A study of attribute frames in broadcast news stories. Journal of Behavioral Decision Making, 18(4), 261-280. https://doi.org/10.1002/bdm.500

Schwarzinger, M., Watson, V., Arwidson, P., Alla, F., \& Luchini, S. (2021). COVID-19 vaccine hesitancy in a representative working-age population in France: A survey experiment based on vaccine characteristics. The Lancet Public Health, 6(4), e210-e221. https://doi.org/10.1016/S2468-2667(21)00012-8

Sinclair, S., \& Agerström, J. (2021). Do social norms influence young people’s willingness to take the COVID-19 vaccine? Health Communication, 1-8. https://doi.org/10.1080/10410236.2021.1937832 
Soroka, S., Fournier, P., \& Nir, L. (2019). Cross-national evidence of a negativity bias in psychophysiological reactions to news. Proceedings of the National Academy of Sciences, 116(38), 18888-18892. https://doi.org/10.1073/pnas.1908369116

Sparkman, G., \& Walton, G. M. (2017). Dynamic norms promote sustainable behavior, even if it is counternormative. Psychological Science, 28(11), 1663-1674. https://doi.org/10.1177/0956797617719950

Sparkman, G., \& Walton, G. M. (2019). Witnessing change: Dynamic norms help resolve diverse barriers to personal change. Journal of Experimental Social Psychology, 82, 238252. https://doi.org/10.1016/j.jesp.2019.01.007

Tankard, M. E., \& Paluck, E. L. (2016). Norm perception as a vehicle for social change. Social Issues and Policy Review, 10(1), 181-211. https://doi.org/10.1111/sipr.12022

Tversky, A., \& Kahneman, D. (1987). Rational choice and the framing of decisions. In R. M. Hogarth \& M. W. Reder (Eds.), Rational choice: The contrast between economics and psychology. (pp. 67-94). University of Chicago Press.

UNICEF Serbia. (2018). Knowledge, attitudes and practices in relation to immunisation of children in Serbia. https://www.unicef.org/serbia/en/reports/knowledge-attitudes-andpractices

WHO Immunization Data portal. (2021). Measles reported cases and incidence. https://immunizationdata.who.int/pages/incidence/MEASLES.html?CODE=SRB\&YEAR

Wickham, H. (2016). ggplot2: Elegant Graphics for Data Analysis. Springer-Verlag New York. https://ggplot2.tidyverse.org/ 
World Health Organization. (2018). 2018 assessment report of the Global Vaccine Action Plan: strategic advisory group of experts on immunization. https://apps.who.int/iris/handle/10665/276967

Xiao, X., \& Borah, P. (2020). Do norms matter? Examining norm-based messages in HPV vaccination promotion. Health Communication, 1-9. https://doi.org/10.1080/10410236.2020.1770506

Yanovitzky, I. (2002). Effects of news coverage on policy attention and actions. Communication Research, 29(4), 422-451. https://doi.org/10.1177/0093650202029004003

YouGov. (2021). COVID-19: Willingness to be vaccinated. https://yougov.co.uk/topics/international/articles-reports/2021/01/12/covid-19-willingness$\underline{\text { be-vaccinated }}$ 